\title{
Korelasi Makna Bahasa Indonesia yang Baik dan Benar dengan Qaulan Ma'rufa dan Qaulan Sadida
}

\section{Ikhsan Abdul Aziz ${ }^{*}$ \\ Deden Ahmad Supendi ${ }^{1}$}

Asep Firdaus ${ }^{1}$

${ }^{1}$ Universitas Muhammadiyah Sukabumi, Kota Sukabumi, Jawa Barat, Indonesia

*email: ikhsanaa27@gmail.com

Received: 15 Juli 2020

Accepted: 30 September 2020

Published: 30 September 2020

doi: $10.22236 /$ imajeri.v3i1.5261

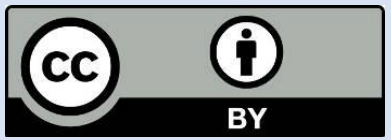

(C) 2020 Oleh authors. Lisensi Imajeri: Jurnal Pendidikan Bahasa dan Sastra Indonesia, Uhamka, Jakarta. Artikel ini bersifat open access yang didistribusikan di bawah syarat dan ketentuan Creative Commons Attribution (CC-BY) license.

(http://creativecommons.org/licenses/by/4.0/).

\section{Abstrak}

Penelitian ini difokuskan pembahasannya pada korelasi makna. Tujuannya untuk mengetahui makna bahasa Indonesia yang baik dan benar dengan qaulan ma'rufa dan qaulan sadida. Jenis metode penelitian yang digunakan adalah kualitatif yang terfokus pada pendeskripsian hasil. Pada proses penelitiannya, keempat istilah tersebut merujuk pada teori-teori mengenai makna kata yang disesuaikan dalam kaidah bahasa, seperti yang termaktub dalam KBBI dan kitab-kitab tafsir Alquran. Bahasa Indonesia yang baik diartikan sebagai bahasa yang dipertuturkan sesuai dengan tempatnya. Bahasa Indonesia yang benar adalah bahasa Indonesia yang mengikuti kaidah kebahasan, yaitu PUEBI dan KBBI. Qaulan ma'rufa sebagai salah satu prinsip kesantunan berbahasa dalam perspektif Alquran mengandung makna pertuturan yang baik dan tidak menyakitkan hati seseorang. Qaulan sadida dimaknai sebagai pertuturan yang benar sesuai dengan Alquran atau hadis.

Kata kunci: Korelasi, Makna, Bahasa, Alquran

\section{Abstract}

This study focuses its discussion on the correlation of meaning. The purpose is to know the meaning of good and true Indonesian language with qaulan ma'rufa and qaulan sadida. The type of research method used is qualitative focused on the description of the results. In the process of research, all four terms refer to theories about the meaning of words adapted in the rules of language, as enshrined in KBBI and the books of tafsir AlQuran. Good Indonesian is defined as the language spoken according to its place. The true Indonesian language is the Indonesian language that follows the rules of language, namely PUEBI and KBBI. Qaulan ma'rufa as one of the principles of language politeness in the perspective of the Qur'an contains the meaning of good speech and does not hurt a person. Qaulan sadida is interpreted as a true speech in accordance with the Qur'an or hadith.

Keywords: Correlation, Meaning, Language, Alquran 


\section{PENDAHULUAN}

Bahasa Indonesia memiliki kedudukan yang teramat penting bagi bangsa Indonesia. Bukti nyatanya adalah lagu kebangsaan Indonesia Raya, undang-undang atau konstitusi negara, hingga dalam dunia akademik yang formal pun memakai bahasa resmi bahasa Indonesia. Dengan beragamnya bahasa daerah di bumi pertiwi ini menjadikan bahasa Indonesia kokoh menjaga harmoni sebagai bahasa persatuan. Menurut Sri (2012) bangsa Indonesia menyadari bahwa kehadiran bahasa Indonesia sangat diperlukan dalam rangka membangun komunikasi antardaerah dan antarsuku yang berbeda latar belakang budaya dan bahasanya.

Pernyataan bahasa Indonesia memiliki kedudukan yang tinggi tentu harus dibuktikan dengan selalu menggunakannya dalam setiap interaksi kehidupan masyarakat Indonesia dalam keadaan formal atau resmi. Namun yang perlu diingat adalah bagaimana memahami cara penggunaannya yang baik dan benar. Maka, ketika seseorang berbahasa tidak boleh serampangan atau asal-asalan. Ada norma-norma yang harus diterapkan agar tidak menimbulkan masalah dan sebagai bentuk perhatiannya pada ranah sosial.

Bahasa Indonesia seharusnya digunakan dengan baik dan benar. Ini sebagai bukti bahwa kita sebagai masyarakat Indonesia menjaga budaya yang telah dipelihara oleh nenek moyang sejak dulu. Juga menghormati pada kaidah yang berlaku. Sikap menghormati bisa dengan cara memelihara dan memakai bahasa Indonesia dengan baik dan benar. Hal ini dapat terwujud oleh penutur dengan taat asas atau taat pada norma berbahasa yang berlaku (Hari Wahyono, 2017). Ibarat pengendara sepeda motor ketika melintas di jalan raya. Pada beberapa lokasi ada rambu-rambu lalu lintas yang harus ditaati. Begitupun dengan bahasa Indonesia yang memiliki kaidah atau aturan dalam penggunaannya.

Dalam perjalanan tumbuh kembangnya, bahasa Indonesia menjadi penghubung antara berbagai keilmuan luar bahasa Indonesia dengan bahasa Indonesia. Masyarakat Indonesia sangat terbantu dengan adanya berbagai terjemahan literatur bahasa asing ke dalam bahasa Indonesia. Teks terjemahan yang isinya berbagai keilmuan baru, menjadi jembatan pengetahuan untuk masyarakat Indonesia agar lebih mudah memahami suatu hal secara kredibel langsung dari sumbernya. Apalagi berbicara tentang suatu keyakinan atau agama. Misal Alquran dengan tafsirnya yang beraneka ragam keilmuan.

Peneliti dalam hal ini, ketika mengkaji beberapa ayat dalam Alquran menemukan suatu istilah yang ada hubungannya dengan kaidah bahasa Indonesia. Yaitu qaulan ma'rufa dan qaulan sadida. Oleh karenaanya masalah utama penelitian ini, tentang bagaimana korelasi antara bahasa Indonesia yang baik dan benar dalam kaidah bahasa Indonesia dengan qaulan ma'rufa dan qaulan sadida dalam tafsir Alquran? Lalu tujuan utama penelitian ini untuk mengetahui korelasi antara bahasa Indonesia yang baik dan benar dalam kaidah bahasa Indonesia dengan qaulan ma'rufa dan qaulan sadida.

Peneliti berharap penelitian ini diharapkan dapat memberikan kontribusi terhadap pengembangan ilmu pada dunia pendidikan bahasa dan sastra Indonesia terutama bidang pengkajian bahasa yang akan digunakan sebagai rujukan oleh peneliti bahasa Indonesia lainnya. Sehingga para peneliti bahasa Indonesia dapat mengetahui bagaimana hubungan bahasa Indonesia yang baik dan benar dengan qaulan ma'rufa dan qaulan sadida. 


\section{METODE}

Penelitian ini menggunakan studi kualitatif yang terfokus pada pendeskripsian hasil. Dalam hal ini peneliti bermaksud menelaah hubungan kaidah yang ada dalam bahasa Indonesia dengan suatu istilah yang ada dalam Alquran, yaitu bahasa Indonesia yang baik dan benar dengan istilah qaulan ma'rufa dan qaulan sadida. Pada proses penelitian keempat istilah tersebut peneliti akan merujuk pada teori-teori mengenai makna dalam kaidah bahasa. Lalu rujukan kedua sebagai penghubung penelitian ini adalah kitab-kitab tafsir Alquran yang telah ditulis oleh para ahli tafsir terkenal.

Analisis yang digunakan dalam penelitian ini adalah analisis makna dan wujud pada suatu istilah sesuai dengan kaidah dan asumsi dari pakar bidangnya masing-masing. Pada analisis bahasa Indonesia yang baik dan benar yang dilakukan oleh peneliti adalah menelaah terkait pemahaman para pakar bahasa Indonesia mengenai kedua istilah tersebut. Adapun untuk istilah qaulan ma'rufa dan qaulan sadida akan peneliti analisis dari pemahaman para mufasirin atau ahli tafsir Alquran. Penelitian pada teks yang sifatnya reseptif dengan ujaran yang sifatnya produktif tentu berbeda. Dalam prosesnya keilmuan semantik dan pragmatik akan turut serta untuk memecahkan rumusan masalah. Substansi penelitian korelasi bahasa Indonesia yang baik dan benar dengan qaulan ma'rufa dan qaulan sadida dengan teori pragmatik adalah melihat bagaimana keempat contoh istilah itu ketika diujarkan.

Buku-buku teori mengenai bahasa Indonesia yang baik dan benar dan kitab-kitab tafsir yang berisi tentang qaulan ma'rufa dan qaulan sadida menjadi rujukan peneliti dalam melakukan penelitiannya. Misalnya dalam menelaah mengenai bahasa Indonesia yang baik dan benar peneliti mengambil teori dari Alwi (2003) yang berjudul "Tata Bahasa Baku Bahasa Indonesia" juga pada telaah makna qaulan ma'rufa dan qaulan sadida peneliti mengambil teori dari Basyir (2016) dengan kedua bukunya yang berjudul "Tafsir Muyassar 1 dan 2".

\section{HASIL DAN PEMBAHASAN}

\section{Makna Bahasa Indonesia yang Baik dan Benar}

Dilihat dari segini etimologi, bahasa Indonesia yang baik sebetulnya mengacu pada kata baik. Maka, terlebih dahulu peneliti akan memaparkan kata baik itu secara individual dari kaidah bahasa Indonesia yang baik. Kata baik dalam kamus besar bahasa Indonesia daring yang termuat dalam situs https://kbbi.kemdikbud.go.id/entri/baik [16 Mei 2020] memiliki makna yang beranekaragam. Dalam situs tersebut kata baik artinya elok; patut; teratur (apik, rapi, tidak ada celanya, dan sebagainya). Termuat dalam tesaurus dalam jaringan yang ada pada situs http://tesaurus.kemdikbud.go.id/tematis/lema/baik [16 Mei 2020], kata baik juga masuk ke dalam banyak kelas kata. Di antaranya adjektiva (kata sifat), adverbia (kata keterangan), nomina (kata benda), dan verba (kata kerja). Kedua pernyataan diatas menafsirkan bahwa kata baik kaya akan makna dan padanannya. Kendati demikian, dalam hal ini cara peneliti dalam menyimpulkan makna kata baik adalah dengan mendefinisikannya secara bersama dengan frasa bahasa Indonesia.

Bahasa Indonesia yang baik berarti bahasa Indonesia yang digunakan dengan baik oleh penutur. Istilah baiknya ini merujuk pada aspek sosial. Seperti apa yang terdeskripsikan di atas, bahasa Indonesia dapat disebut baik adalah bahasa yang sesuai dengan golongan bahasa 
masyarakat setempatnya. Dalam makna lain bahasa Indonesia yang baik adalah bahasa Indonesia yang sepaham antara penutur dan mitra tutur. Oleh karenanya, bahasa Indonesia memang harus digunakan secara baik agar memudahkan untuk saling mengerti antara satu orang dengan yang lainnya.

Penggunaan bahasa Indonesia yang baik perlu dilengkapi dengan penggunaan bahasa Indonesia yang benar. Bahasa Indonesia yang benar adalah penggunaan bahasa yang sesuai dengan pedoman kaidah kebahasaan yang berlaku. Muslich (2010) mengatakan bahwa anjuran agar kita "berbahasa dengan baik dan benar" dapat diartikan pemakaian ragam bahasa yang serasi dengan sasarannya dan mengikuti kaidah yang betul. Bahasa dikatakan benar jika setiap ejaan yang dipertuturkan sesuai dengan ejaan yang ada pada kaidah kebahasaan. Ada kaidah khusus yang membakukan suatu bahasa agar terkatagorikan benar. Kaidah ini termaktub dalam buku pedoman umum ejaan bahasa Indonesia (PUEBI) dan kamus besar bahasa Indonesia (KBBI). Dua pedoman ini selalu dipakai oleh setiap akademisi dalam menentukan suatu bahasa agar yakin dinilai benar sesuai kaidah.

Dalam hal ini peneliti juga akan membahas makna benar dilihat dari segini etimologi, karenanya bahasa Indonesia yang benar juga merujuk pada kata benar. Kata benar dalam KBBI daring yang termuat dalam situs https://kbbi.kemdikbud.go.id/entri/benar [16 Mei 2020] memiliki makna yang cukup banyak. Salahsatunya, dalam situs daring tersebut benar artinya sesuai sebagaimana adanya (seharusnya); betul; tidak salah. Sebagai pelengkap peneliti juga akan menyampaikan padanan dari kata benar, termuat dalam tesaurus dalam jaringan yang ada pada situs http://tesaurus.kemdikbud.go.id/ tematis/lema/benar (16 Mei 2020). Kata benar termasuk ke dalam beberapa kelas kata yaitu: adjektiva (kata sifat), adverbia (kata keterangan), dan verba (kata kerja). Diantara kata-kata yang sepadan adalah akurat, asli, betul, dan jujur. Kemudian, seperti halnya kata baik yang telah dibahas sebelumnya, kata benar juga kaya akan makna.

Peneliti menyimpulkan bahwa sebenar-benarnya bahasa Indonesia adalah suatu ejaan yang sama persis dengan apa yang termaktub dalam KBBI. Dan setiap penggunaan bahasanya mengikuti kaidah dalam PUEBI. Namun yang menjadi catatan, kedua kaidah atau pedoman ini mutlak harus merujuk pada KBBI dan PUEBI yang bersumber dari terbitan badan bahasa Kemendikbud Republik Indonesia. Hal ini dikarenakan penilaian sahih atas kebakuan suatu ejaan hanya dapat diakurasikan pada KBBI dan PUEBI yang telas dibakukan oleh badan bahasa Kemendikbud RI secara resmi. Dengan kedua pedoman ini terbantulah setiap orang untuk menilai kebenaran bahasanya.

Seperti yang telah peneliti utarakan di atas, bahasa Indonesia yang baik dan bahasa Indonesia benar memang merupakan suatu kaidah kebahasaan yang mestinya selalu diperhatikan oleh setiap pengguna bahasa. Sebagai manusia yang selalu menggunakan bahasa dalam keseharian hidup, hendaknya orang-orang memahami dan dapat mengaplikasikan pentingnya berbahasa dengan baik dan benar. Kendati kenyataannya beberapa masyarakat ada yang kurang memperhatikan hal ini, namun seorang akademisi seharusnya bisa menyampaikan keilmuan ini kepada sesama untuk menunjang tercapainya norma kebahasaan yang baik dan benar. Baik dan benar ini menjadi korelasi yang utuh sebagai bahan rujukan kaidah suatu kebahasaaan. Maka ketika hendak berbahasa Indonesia, tidak hanya dilihat secara baik saja namun mesti juga dilihat secara benar. 


\section{Makna Qaulan Ma'rufa dan Qaulan Sadida}

Qaulan ma'rufa sebagai bagian dari prinsip pertuturan masyarakat muslim memiliki arti suatu perkataan yang baik. Sofyan dalam artikel ilmiahnya (Sauri) mengatakan qaulan ma'rufa mengandung arti perkataan yang baik, yaitu perkataan yang sopan, halus, indah, benar, penuh penghargaan, dan menyenangkan, serta sesuai dengan hukum dan logika. Sauri (2006) mengatakan bahwa ucapan yang baik adalah ucapan yang diterima sebagai sesuatu yang baik dalam masyarakat lingkungan penutur. Dalam bahasa Indonesia pun kata makruf yang telah baku mempunyai arti baik. Hal ini sesuai dengan apa yang tercatat pada KBBI daring, https://kbbi.kemdikbud.go.id/entri/makruf [17 Mei 2020] makruf artinya perbuatan baik; jasa. Untuk mengetahui arti dari qaulan, kali ini peneliti memakai kamus dalam jaringan al maany sebagai sumber yang dapat dipercaya. Pada situs https://almaany.com/id/dict/ar-id/ 2017 Mei 2020] qaulan atau dalam tulisan bahasa Arabnya قول memiliki arti perkataan, pernyataan, atau pepatah. Lalu pada situs https://almaany.com/id/dict/ar-id/ معروف [17 Mei 2020] ma'rufa atau dalam tulisan bahasa Arabnya معروف memiliki arti kebaikan. Maka, secara sederhana qaulan ma'rufa/ معروف قول dapat dipahami sebagai suatu perkataan yang berisikan hal-hal baik.

Tidak cukup sampai di sini dalam memaknai qaulan ma'rufa, lebih jelas peneliti akan membahasnya bersamaan dengan tafsir Alquran. Dalam hal ini ketika menelaah mushaf Alquran, qaulan ma'rufa tertulis salah satunya di dalam Quran surat Al Baqarah ayat 263 yang berbunyi:

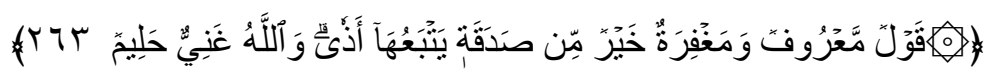

"Perkataan yang baik dan pemberian maaf lebih baik dari sedekah yang diiringi dengan sesuatu yang menyakitkan (perasaan si penerima). Allah Maha Kaya lagi Maha Penyantun.” QS. Al Baqarah [2]:263

Kandungan ayat mulia di atas berisi anjuran untuk berkata yang baik dan memberikan maaf ketika menolak sedekah agar tidak menyakiti perasaan penerima atau seseorang yang memintanya. Sesuai dalam Alquran, kalimat tersebut termasuk pada konteks penolakan sedekah yang dilakukan secara baik. Dalam hal ini peneliti menegaskan bahwa pengambilan data dalam proses analisis qaulan ma'rufa dan qaulan sadida disesuaikan dengan apa yang termaktub pada kitab tafsir yang cukup masyhur. Kitab yang dipakai adalah kitab tafsir Ibnu Katsir, kitab tafsir Muyassar, dan kitab tafsir Al Wasith.

Termuat dalam tafsir Ibnu Katsir yang diterjemahkan oleh Ghoffar (2017), qaulan ma'rufa dalam Alquran surat Al Baqarah [2]:263 mengandung arti perkataan yang baik. Perkataan yang baik yaitu berupa kata-kata yang baik dan doa bagi orang muslim. Qaulan ma'rufa pada ayat di atas memberikan jawaban kepada seseorang ketika terjadi situasi keengganan untuk memberi kepada seseorang yang menurutnya tidak baik untuk diberi. Penolakan ini dilandasi oleh faktor internal dan eksternal. Pada faktor internal, seseorang enggan memberi karena tidak memiliki sesuatu untuk diberi. Dan pada faktor eksternal, seseorang enggan memberi karena hal-hal yang ada pada diri peminta seperti sikap, perilaku, ucapan, dan pakaiannya sama sekali tidak membuat iba dan ingin diberi oleh pemberi. Oleh karenanya seseorang yang dimintai sesuatu oleh peminta akan menolaknya jika tidak bisa memberi. Pada kondisi seperti ini kedua belah pihak tidak menginginkan terjadinya 
perselisihan. Maka, penolakan yang dilakukan harus dengan lembut, memberi maaf, tersenyum, dan mendoakan kebaikan untuknya.

Ashim dan Karimi juga menerjemahkan tafsiran Basyir dalam kitab tafsir Muyassar 1 sesuai dalil Alquran surat Al Baqarah [2]:263 di atas. Ashim dan Karimi (2016) menerjemahkan perkataan Basyir bahwa perkataan baik dan pemberian maaf terhadap sikap yang tampak dari peminta-minta berupa desakan dalam meminta itu lebih baik daripada sedekah. Allah Maha Kaya, tidak membutuhkan sedekah-sedekah hamba-Nya, lagi Maha Penyantun, tidak menyegerakan siksaan pada mereka. Sementara itu dalam tafsir Al Wasith jilid 1, Muhtadi (2013) menerjemahkan ayat di atas dengan mengatakan bila seseorang tidak hendak bersedekah, hendaklah ia menolak dengan baik-baik, hendaklah berkata yang sopan dan makruf tanpa menyakiti.

Berdasarkan kajian dan analisis di atas, peneliti dalam hal ini akan menyimpulkan makna dari qaulan ma'rufa. Qaulan ma'rufa mengandung arti perkataan yang baik. Perkataan yang baik artinya suatu ucapan yang tidak menimbulkan keburukan atau masalah. Berbicara dengan baik-baik adalah hal pantas yang harus dilakukan oleh seseorang ketika ingin menolak sesuatu. Tujuannya supaya kedua belah pihak bisa berdamai dan tidak terjalin suatu konflik. Sehingga tidak ada yang tersakiti dan bisa saling menerima terhadap keadaan yang telah terjadi.

Selanjutnya adalah analisis makna qaulan sadida. Qaulan sadida dapat diartikan sebagai suatu perkataan yang benar. Rahmat (1994) mengungkap makna qaulan sadida dalam arti pembicaraan yang benar, jujur, lurus, tidak sombong, tidak berbelit-belit. Ucapan yang benar dan tidak menyakiti dapat dengan mudah mempengaruhi seseorang yang sedang mendengarkan atau mitra tutur yang menyimak pertuturan. Pasalnya ucapan tersebut akan masuk ke dalam hati mitra tutur yang kemudian akan diresapi secara dalam. Sauri (2006) berpendapat qaulan sadida, QS. An Nisa [4]:9, yaitu berbicara dengan benar. Sauri (2006) juga mengutip perkataan Hamka mengenai definisi qaulan sadida, yaitu ucapan tepat yang timbul dari hati yang bersih, sebab ucapan adalah gambaran dari apa yang ada di dalam hati. Seseorang yang berhati bersih dan terbebas dari segala penyakit hati pasti akan berkata benar. Sehingga setiap tutur kata yang terucap akan mudah diterima oleh setiap mitra tutur.

Qaulan sadida atau dalam penulisan bahasa Arabnya سديد قو لا merupakan dua kata yang memiliki makna khusus. Jika ditelaah secara mandiri kata قولا seperti qaulan yang telah dipaparkan di atas, yaitu bermakna perkataan, pernyataan, atau pepatah. Sadida atau سديد mempunyai makna suatu hal yang benar. Hal ini sesuai dengan apa yang termaktub pada situs https://almaany.com/id/dict/ar-id/سديد/18 Mei 2020] yang berarti tepat, relevan, siap, benar, betul, dan serasi. Oleh karenanya qaulan sadida bisa diartikan suatu perkataan yang memiliki nilai kebenaran. Lebih jelas peneliti akan membahasnya bersamaan dengan tafsir Alquran. Ketika menelaah mushaf Alquran, qaulan sadida tertulis salah satunya dalam Alquran surat Al Ahzab ayat 70 yang berbunyi:

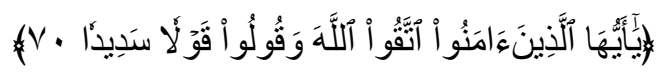

"Hai orang-orang yang beriman, bertakwalah kamu kepada Allah dan katakanlah perkataan yang benar.” QS. Al Ahzab [33]:70 
Dilihat dari konteksnya, tergambar jelas ayat tersebut menerangkan tentang seruan kepada orang beriman untuk bertakwa kepada Allah 'Azza wa Jalla dan perintah untuk mengucapkan perkataan yang benar. Ayat ini juga memberikan indikasi bahwa setiap ucapan yang dipertuturkan oleh orang beriman dan bertakwa isinya berupa kebenaran yang dapat menjadi pegangan banyak orang. Karenanya, dengan tingkat validitas yang tinggi maka setiap apa yang diucapkan akan terimplementasikan pada setiap gerak. Secara tersirat ayat di atas juga menyerukan kepada orang beriman untuk mengajak sesama kepada kebenaran.

Dalam analisisnya, qaulan sadida juga akan ditelaah pada tafsir-tafsir yang masyhur. Pertama, mengacu pada tafsir Ibnu Katsir jilid 7, qaulan sadida artinya perkataan yang benar, yaitu yang lurus tidak bengkok dan tidak menyimpang (Ghoffar, 2017). Kedua, dalam tafsir Muyassar 2, Ashim dan Karimi (2016) menerjemahkan perkataan Basyir merujuk pada Alquran surat Al Ahzab [33]:70 di atas, bahwa wahai orang-orang yang membenarkan Allah dan Rasul-Nya, serta melaksanakan syariat-Nya, taatilah Allah dan jauhilah kemaksiatan kepada-Nya agar kalian tidak ditimpa hukuman-Nya. Dan ucapkanlah dalam segala urusan kalian dan keadaan kalian kata-kata yang lurus, sesuai dengan kebenaran, bersih dari kedustaan, dan kebatilan. Ketiga, dalam tafsir Al Wasith jilid 3, Muhtadi (2013) menerjemahkan ayat di atas dengan mengatakan ini janji Allah, Ia akan membalas tutur kata yang benar dengan memperbaiki amal perbuatan dan mengampuni dosa.

Jika diperhatikan, tafsir dalam kitab Ibnu Katsir jilid 7 sesuai temuan pada paragraf di atas dengan tegas mengatakan qaulan sadida adalah suatu perkataan yang benar. Kitab Ibnu Katsir sebetulnya banyak memberikan penjelasan pada setiap ayat Alquran. Meskipun demikian, pembahasannya yang rinci pada kitab Ibnu Katsir dapat memudahkan peneliti untuk menemukan makna qaulan sadida. Peneliti hanya mengutip secara singkat sesuai data yang dicari. Kemudian, pada tafsir Muyassar 2 qaulan sadida dimaknai sebagai perkataan yang lurus dan bersih dari kedustaan. Hal ini sebagaimana yang telah peneliti sampaikan, bahwa kebenaran artinya hal-hal yang jauh dari kebohongan. Dan dalam tafsir Al Wasith jilid 3, istilah qaulan sadida merujuk pada janji Allah. Allah Azza wa Jalla akan membalas perkataan benar seseorang dengan diperbaikinya amal perbuatan dan diampuni dosanya.

Berdasarkan kajian dan analisis di atas, peneliti dalam hal ini akan menyimpulkan makna dari qaulan sadida. Qaulan sadida mengandung arti perkataan yang benar. Perkataan yang benar artinya suatu ucapan yang tidak terdapat hal-hal dusta di dalamnya. Berbicara dengan benar adalah hal pantas yang harus dilakukan oleh seseorang ketika ingin menyampaikan sesuatu. Apalagi pada kondisi dalam persidangan atau sedang diinterogasi oleh pihak berwenang. Tujuannya supaya informasi yang disampaikan penutur kepada mitra tutur dapat menjadi pegangan pada suatu urusan. Sehingga apa yang terucap pada seseorang.

\section{KESIMPULAN}

Berdasarkan hasil penelitian dan pembahasan pada segi definisi dari keempat istilah yang sudah teruraikan di atas peneliti meyakini bahwa bahasa Indonesia yang baik dan benar dengan qaulan ma'rufa dan qaulan sadida memiliki hubungan atau korelasi. Penggunaan bahasa Indonesia yang baik tidak bisa dijauhkan dengan penggunaan bahasa Indonesia yang benar. Qaulan ma'rufa dan qaulan sadida juga tidak bisa dipisahkan dalam penerapannya. Pada hakikatnya bahasa Indonesia yang baik memiliki hubungan makna dengan qaulan 
ma'rufa yang berarti pertuturan yang baik. Istilah baik ini terkategorikan baik dari aspek sosial, yaitu dapat diterima oleh penutur dan mitra tutur karena selaras dengan bahasa disekitarnya. Maka bahasa Indonesia yang digunakan secara baik dapat juga dikatakan bahasa yang digunakan secara ma'rufa.

Bahasa Indonesia yang benar juga memiliki hubungan dengan qaulan sadida yang berarti pertuturan yang benar. Istilah benar ini merujuk pada kaidah-kaidah yang menjadi pedoman bersama dalam pemakaian bahasa dan pertuturan yang sesuai dengan nilai-nilai kebenaran dan keyakinan. Maka bahasa Indonesia yang digunakan secara benar juga dapat dikatakan bahasa yang digunakan secara sadida. Bahasa Indonesia yang benar dengan qaulan sadida merupakan kaidah yang telah dibakukan dalam buku pedoman atau kitab. Dengan memahami korelasi makna dari kempat istilah ini, seseorang dapat mengaplikasikan Bahasa Indonesia yang baik dan benar berikut qaulan ma'rufa dan qaulan sadida yang dapat menghasilkan suatu pahala keberkahan.

\section{DAFTAR PUSTAKA}

Ashim, M., \& Karimi, I (Penerjemah). 2016. Tafsir Muyassar 1 (Memahami Alquran dengan Terjemahan dan Penafsiran Paling Mudah). Jakarta: Darul Haq.

Ashim, M., \& Karimi, I (Penerjemah). 2016. Tafsir Muyassar 2 (Memahami Alquran dengan Terjemahan dan Penafsiran Paling Mudah). Jakarta: Darul Haq.

Ghoffar, M. A. (Penerjemah). 2017. Tafsir Ibnu Katsir Jilid 1. Jakarta: Pustaka Imam AsySyafi'i.

Ghoffar, M. A. (Penerjemah). 2017. Tafsir Ibnu Katsir Jilid 7. Jakarta: Pustaka Imam AsySyafi'i.

Hari Wahyono. (2017). Berbahasa Indonesia Dengan Baik dan Benar (Antara Harapan dan Kenyataan). 273-278.

Kamus Daring Al Maany. Tersedia: https://www.almaany.com/id/dict/ar-id

KBBI Daring. Tersedia: https://kbbi.kemdikbud.go.id

Muhtadi, dkk. (penerjemah). 2013. Tafsir Al Wasith 1 (Al Fatihaah-At taubah). Jakarta: Gema Insani.

Muhtadi, dkk. (penerjemah). 2013. Tafsir Al Wasith 3 (Al Qashash-An Naas). Jakarta: Gema Insani.

Muslich, M. 2010. Garis-Garis Besar Tatabahasa Baku Bahasa Indonesia. Bandung: Refika Aditama.

Sauri, S. 2006. Pendidikan Berbahasa Santun. Bandung: PT. Ganesindo.

Sri. 2012. Bahasa Indonesia dalam Berbagai Perspektif Dilengkapi dengan Teori, Aplikasi, dan Analisis Penggunaan Bahasa Indonesia Saat Ini. Yogyakarta: CV. Andi Offset.

Sofyan S. (n.d.). Pendekatan Semantik Frase Qaulan Sadida, Ma'rufa, Baligha, Maysura, Layyina, dan Karima untuk Menemukan Konsep Tindak Tutur Qurani. 1(4), 53

Tesaurus Daring. Tersedia: http://tesaurus.kemdikbud.go.id/tematis 